\title{
Spatial and Temporal Variation in Climate Trends in the Kyoga Plains of Uganda: Analysis of Meteorological Data and Farmers' Perception
}

\author{
Oketcho Chombo', Shuaib Lwasa ${ }^{1}$, Moses Tenywa ${ }^{2 *}$ \\ ${ }^{1}$ Department of Geography, Geoinformatics and Climate Sciences, School of Forestry, Environmental and Geographical Sciences, \\ College of Agriculture and Environmental Sciences, Makerere University, Kampala, Uganda \\ ${ }^{2}$ Department of Agricultural Production, School of Agricultural Sciences, College of Agriculture and Environmental Sciences, \\ Makerere University, Kampala, Uganda \\ Email: *ojosephat@gmail.com
}

How to cite this paper: Chombo, O., Lwasa, S., \& Tenywa, M. (2020). Spatial and Temporal Variation in Climate Trends in the Kyoga Plains of Uganda: Analysis of Meteorological Data and Farmers' Perception. Journal of Geoscience and Environment Protection, 8, 46-71.

https://doi.org/10.4236/gep.2020.81004

Received: November 14, 2019

Accepted: January 12, 2020

Published: January 15, 2020

Copyright $\odot 2020$ by author(s) and Scientific Research Publishing Inc. This work is licensed under the Creative Commons Attribution International License (CC BY 4.0).

http://creativecommons.org/licenses/by/4.0/

\begin{abstract}
With global warming now a certainty, it's important to investigate climate change elements at the local level so as to enable stake holders adapt in order to sustain their livelihoods. This study investigated local climate changes, farmers' perception of the changes and factors affecting perception to climate change in the Kyoga plains of Uganda. Monthly maximum temperature, minimum temperature and total rainfall from four meteorological stations within the study area for period 1984-2014 were obtained to analyse seasonal, annual and decadal trends in rainfall and temperature while a survey based on 384 randomly selected farmers was carried out to investigate the perception of variation in climate change trends among small holder farmers of different socioeconomic characteristics across the Kyoga plains. Multi stage random sampling was applied in the selection of the population sample. Non parametric analysis (Mann Kendall test) was used for analyzing trends and testing significance. In the survey, farmers were asked their observations about the local climate using structured questionnaires and these were analysed using descriptive statics. Logistics regression was then used to identify the factors that determined the perceptions of farmers on climate change. Overall, trends in monthly temperature are increasing over the years but not significantly while rainfall is decreasing but equally not significantly. Seasonal and decadal temperature had significant positive trends at different stations and sub zones over the years. $67 \%$ of the farmers realised a decrease in rainfall while $56.8 \%$ perceived an increase in temperature across the agroecological zone. $56.3 \%$ perceived declining rainfall and 52\% realized increasing tem-
\end{abstract}


perature in the southern sub zone while $42 \%$ realised a decrease in rainfall and $40.6 \%$, an increase in temperature in the northern sub zone. Belonging to a group and age has significant positive effect on farmers' perception of climate while farming experience and access to extension workers had a significant negative effect. The results suggest the need for strengthening networking among farmers for peer learning and support and location specific intervention measures to improve perception and adaptation to climate for each of the sub zones.

\section{Keywords}

Climate Change, Small Holder Farmers, Spatial Differentiation, Perception

\section{Introduction}

Climate change will affect the productivity of crop species and their geographic distribution in the world where production depends on climate variables like temperature, precipitation and light (Rosenzweig \& Tubiello, 2007). Warming temperatures, changes in rainfall patterns, frequent climate extremes such as drought and floods all directly and mostly negatively affect agricultural productivity and production levels (Abraha, 2015; Elbehri, Genest, \& Burfisher, 2011); (Egeru et al., 2014). The warming trend affects the process of photosynthesis and respiration, provides habitat for breading and multiplication of insects and diseases, fast growth of weeds and the thermal and hydrological regimes that govern agricultural systems and this affects food production directly due to changed agroecological conditions (Foster \& Rosenzweig, 2004). There is evidence of changing trends in agroclimatic indices (Egeru et al., 2014) (Turyahabwe, Tumusiime, Kakuru, \& Barasa, 2013) especially those directly related to temperature like decreases in length of the growing season (Epule, Ford, Lwasa, \& Lepage, 2017) (Bernstein et al., 2008). Climate variability is already negatively impacting smallholder farmers, notably the decline in crop yields and in more severe cases, complete crop failure (Epule et al., 2017); (Stocker et al., 2013) with the most vulnerable being rain-fed crop systems (Lwasa et al., 2014).

Uganda is highly vulnerable to rainfall variability and climatic shocks like droughts and floods (Ministry of Water and Environment, 2002), (Okonya, Syndikus, \& Kroschel, 2013) (Bomuhangi, Nabanoga, Namaalwa, Jacobson, \& Abwoli, 2016). During the period 2001-2011, temperature increased by $1^{\circ} \mathrm{C}$ and there is evidence in the region for larger variations in temperature and rainfall in future. Climate projections based on two emission scenarios (A1b and A2) from at least five General Circulation Models indicate an increase in temperature for the next 30 years and more rainfall in the 2010-2039 periods (Eike, Roeland, Swen, Sang, \& Musau, 2014); (Bomuhangi et al., 2016).

Uganda is a large country with ten agroecological zones according to the $\mathrm{Na}$ tional Agricultural Research Organisation (NARO) classification (Chombo, 
Lwasa, \& Makooma, 2018) with climate features resulting from its location and altitude variations. This implies that the regional and continental-scale studies available are too course for relevance to the local land use and management (Stampone, Hartter, Chapman, \& Ryan, 2011), because large-scale climate projections and trend generalizations may not necessarily reflect situations at the local and agroecological level. Studies on climate change trends have been carried out in different parts of the country. In their study of trends and variability in localized precipitation Kibale, (Stampone et al., 2011) found out that spatial patterns in seasonal rainfall within western Uganda are not homogenous within such zones but varied between stations and the climatological trends in annual rainfall differed in magnitude and direction from seasonal trends. (Nsubuga, Olwoch, \& de Rautenbach, 2011) on their part explored climatic trends at Namulonge 1947-2009 and found out that both minimum and maximum temperature has been increasing over the years while total rainfall has been decreasing. Another study by (Nsubuga et al., 2014) on the nature of rainfall in the main drainage basins of Uganda established that there is a marked contrast in seasonal cycle between sub basins that lie over and below latitude $2^{\circ} \mathrm{N}$, that is, the southern and northern basins. (Kizza, Rodhe, Xu, Ntale, \& Halldin, 2009) on the other hand examined the temporal rainfall variability in the Lake Victoria basin during the $20^{\text {th }}$ century and found a positive trend in total rainfall in most stations to the north of Lake Victoria especially during the short rains. These studies, though confined within the central and western parts of the country, are good indicators of how climate elements vary across locations in Uganda.

With global warming now a certainty, it's important to make investigations on climate change elements at the local level so as to enable stake holders adapt. Whereas there are studies on climate change trend analysis in Uganda, many of them for instance, (Stampone et al., 2011), (Kizza et al., 2009) and (Nsubuga et al., 2014) are mainly on rainfall characteristics and even those that combine rainfall and temperature like (Nsubuga et al., 2011) do not compare it with local farmers' perception let alone establish the factors that influence these perceptions and yet adaptation to climate change requires that farmers first realise that climate has altered. This is important since how local people perceive climate change determines how they formulate strategies to reduce possible impacts of those changes on their livelihoods (Deressa, Ringler, \& Hassan, 2010, Abrha, 2015, Gebre, Kindie, Girma, \& Belay, 2013, Mugagga, 2017). Assessing trends in climate characteristics based on past scientific records together with the perception of the local community is essential to develop policy recommendations for future adaptation strategies (Patiño \& Gauthier, 2009, Mubangizi, Kyazze, \& Mukwaya, 2017, Maddison, 2007).

Some attempts have been made to analyse farmers' perception of climate change in Uganda for instance; (Mubangizi et al., 2017, Bomuhangi et al., 2016) and (Mugagga, 2017) investigated farmers' perceptions to local climate change and how they influence adaptation strategies. However, whereas (Mubangizi et al., 2017) and (Bomuhangi et al., 2016) determined how consistent farmers' per- 
ceptions are with statistical realities, (Mugagga, 2017) did not. On the other hand, only (Mugagga, 2017) determined how socioeconomic factors influence farmers' perception of climate change while the others did not. All the three did not determine how both climate change trends and the factors that influence farmers' perception of the changes in these trends vary from place to place within the study. It is therefore more useful when farmers' perceptions of climate change trends are surveyed and compared with statistical analysis of climate trends and factors affecting these perceptions are explicitly identified. It is even much more useful when we consider how the farmers' perceptions of climate change trends in comparison with statistical analysis and the determinants of these perceptions vary from place to place within the study area. Therefore, the objectives of this study were to; 1) investigate trends and spatial variation of climate change, 2) identify the farmers' perception on trends of local climate and compare them with findings of statistical analysis and 3), identify the determinants of farmers' perception on climate change and asses how they vary among farmers of different socioeconomic characteristics in the different parts of the Kyoga plains of Uganda.

\section{Materials and Methods}

\subsection{Profile of the Study Area}

The study was conducted in the Kyoga plains of Uganda which is one ten agroecological zones in the country according to the National Agricultural Research Organization (NARO) classification (Wortmann \& Eledu, 1999), Figure 1. The zone comprises of several districts including Tororo and Pallisa, which were chosen for the study.

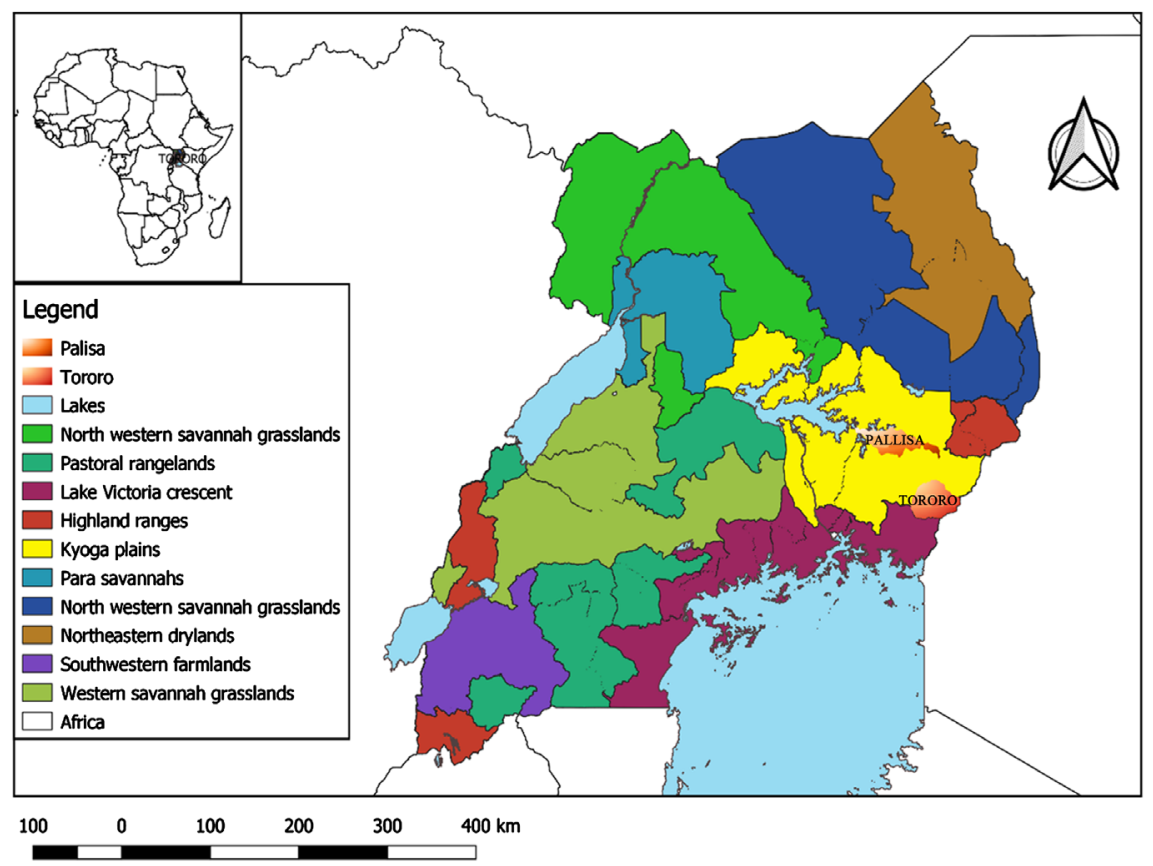

Figure 1. Map showing the study area. 
In the southern part of the zone (Tororo), the average rainfall is 1215 - 1238 $\mathrm{mm}$ which comes in two seasons that is, March-May and August-November with one dry season, between December to February. Evaporation exceeds rainfall during the dry months while during the rainy season; rainfall is greater or equal to evaporation.

In the northern part of the agroecological zone (Pallisa), there is one rainy season, that is, March to November and one dry season, December to March. Evaporation exceeds rainfall during dry months and rainfall is greater or equal to evaporation during dry months. The temperature ranges between $24-36^{\circ} \mathrm{C}$. On the whole, altitude ranges from $914-1800$ metres above sea level. The land is mainly flat and swampy while the soils range from low to moderate productivity (Authority, 2006/07).

The Kyoga plains were chosen because it is an important focal area for Uganda given its importance in the Nile basin. The area has important resources for production for example fresh water, vegetation, soil, to mention but a few and yet there are significant differences in human welfare indicators such as health, population, poverty, food security and others (McSweeney, New, Lizcano, \& Lu, 2010). The Kyoga plains have a fast-growing population with a growth rate of $4 \%-6 \%$ with the poverty and food security situation worse than the national average. Northern Uganda (Lira, Apac, among others), which form part of the Kyoga plains, is the poorest region in the country, with a poverty level of $75.8 \%$ of the population.

Two districts were chosen from the zone purposively, one from the northern sub zone (Pallisa) and one from the southern sub zone (Tororo), respectively. because these districts are particularly vulnerable to climate change and given their proximity to other districts, it is hoped that results from these will reflect the conditions in the others.

\subsection{Data and Sampling/Analytical Framework}

The study used the cross-sectional research design. Structured questionnaires were used to elicit data from the small holder farmers on their perception of climate change.

Monthly minimum and maximum temperature and monthly precipitation data was obtained from the Uganda National Meteorological Authority (UNMA) in Kampala, Uganda for 30 years (1984-2014) for the study. The World Meteorological Organization (WMO) recommended a minimum of a 30 year data series for a study to detect trends in hydro-climatic time series (Abrha, 2015). Temperature and precipitation data were obtained for four meteorological stations distributed across the agroecological zone namely, Tororo, Soroti, Lira and Jinja. Jinja and Tororo are in the southern sub zone while Soroti and Lira are in the northern subzone of the Kyoga plains ecological zone (Table 1). Data from the other stations from within the region like Serere, Kamuli and Mbale that could have been used were reported to be having so much gaps hence only the four stations were relied upon. 
Table 1. Hypothesized explanatory variables and their descriptive statistics for logistics regression model.

\begin{tabular}{|c|c|c|c|c|}
\hline Independent Variables & Unit & Mean & Std. Dev. & Expected sign \\
\hline Age & Continuous & 43.79 & 13.82 & $+1-$ \\
\hline Farming experience & Continuous & 25.90 & 14.12 & $+1-$ \\
\hline Gender & Dummy: $1=$ Male, $2=$ Female & 1.40 & 0.49 & $+1-$ \\
\hline Annual income & Continuous & $1,147,472.00$ & $1,450,342.00$ & + \\
\hline Group membership/social network & Dummy: $1=$ Yes, $0=$ No & 0.68 & 0.47 & $+1-$ \\
\hline Access to extension workers & Dummy: $1=$ Yes, $2=$ No & 1.46 & 0.50 & + \\
\hline Access to credit & Dummy: $1=$ Yes, $2=$ No & 1.42 & 0.49 & + \\
\hline Education level & $\begin{array}{c}1=\text { No formal education, } 2=\text { primary education, } \\
3=\text { Secondary education, } 4=\text { Higher }\end{array}$ & 2.17 & 0.77 & $+1-$ \\
\hline Farm equipment/technology & Continuous & 1.01 & 0.97 & $+1-$ \\
\hline
\end{tabular}

A survey was conducted in the study area in which three hundred and eighty-four respondents were chosen across the two districts of study. Two sub counties were chosen per district and from each of these, two parishes were chosen then three villages were chosen from each parish. Sixteen respondents were then chosen from each village basing on the list of residents from the LC one chairperson. This was first stratified to male and female headed households and from each substratum, an appropriate number randomly picked to make the sixteen. These were then interviewed using a semi structured questionnaire with the help of five local interviewers.

The survey involved a detailed investigation into how farmers of different socioeconomic characteristics perceive climate change. The farmers were asked if they had noted any changes in climate, that is, increase or decrease in temperature, no change in temperature levels; increase or decrease in precipitation, no changes in precipitation, changes in the onset and cessation of rains; increases or decrease in the frequency of drought, no changes in the frequency of drought; increase or decrease in the frequency of floods and, no change in the frequency of floods in the last ten years. Ten years were thought to be a period short enough for the farmers to be able to have reasonable memory of the climate events.

Prior to the survey, a reconnaissance was done with a view of establishing the main climate risks that are common in the area against which farmers' perception could be tested. This was to validate the indicators that had been identified from literature and the outcome of the reconnaissance helped to strengthen the survey tool. The survey was conducted with the help of five interviewers who were trained in data collection methods of survey and use of Global Positioning System (GPS) for coordinate readings of household locations.

\subsection{Data Analysis}

\subsubsection{Mann Kendall}

The Mann Kendall analysis is a statistical test widely used for analysing trends in 
climatologic (Abrha, 2015); (Djaman, Koudahe, \& Ganyo, 2017); (Bhuyan, Islam, \& Bhuiyan, 2018); (Tabari \& Talaee, 2011) and hydrologic time-series studies (Yue \& Wang, 2004); (Yue \& Hashino, 2003). There are two advantages of using this test. First, it is a nonparametric test and does not require data to be normally distributed. Second, it has low sensitivity to abrupt breaks due to inhomogeneous time series (Tabari \& Talaee, 2011). Any data reported as non-detects are included by assigning them a common value that is smaller than the smallest measured value in the data set (Blackwell \& Glynn, 2017). Data values are evaluated as an ordered time series. Each data value is compared to all subsequent data values. The initial value of the Mann-Kendall statistic, $S$, is assumed to be 0 (that is, no trend). If a data value from a later period is higher than a data value from an earlier period, $S$ is incremented by 1 . On the other hand, if the data value from a later period is lower than a data value sampled earlier, $S$ is decremented by 1 . According to this test, the null hypothesis $\left(H_{0}\right)$ assumes that there is no trend $(S=0)$ and this is tested against the alternative hypothesis $\left(H_{1}\right)$, which assumes that there is a trend $(S \neq 0)$ (Önöz \& Bayazit, 2012). Given that $x_{1}, x_{2}, x_{3}, \cdots, x_{n}$ represent $n$ data points where $x_{j}$ represents the data point at time $j$, the Mann-Kendall statistic $(S)$ is given by:

$$
S=\sum_{i=1}^{n-1} \sum_{j=k+1}^{n} \operatorname{sgn}\left(x_{j}-x_{i}\right)
$$

where; $s$ is the Mann Kendal value, $x_{j}$ and $x_{i}$ are the data values for the years $j$ and $i(j>i)$ and $n$ is the length of the time series. A positive/negative value of $S$ indicates an upward/downward trend.

It is assumed that for data set $n \geq 10$, the statistics $S$ is approximately normally distributed with the mean and variance computed as

$$
E(s)=0
$$

The variance $\left(\sigma^{2}\right)$ for $S$-statistics, in a situation where there may be ties (same values) in the $x$ value is given by:

$$
\operatorname{Var}(s)=\frac{n(n-1)(2 n+5)-\sum_{i=1}^{m} t_{i}\left(t_{i-1}\right)\left(2_{t 1}+5\right)}{18}
$$

where summation in the numerator is used only if the data series contains tied values, $m$ is the number of tied groups and $t_{i}$ is the data points. The standard statistic $Z_{s}$ is calculated as:

$$
Z_{s}= \begin{cases}\frac{s-1}{\sqrt{\operatorname{VAR}(S)}} & \text { If } s>0 \\ 0 & \text { If } s=0 \\ \frac{s+1}{\sqrt{\operatorname{VAR}(S)}} & \text { If } s<0\end{cases}
$$

The presence of a statistically significant trend is evaluated using the Mann-K value. In a two-sided test for trend, the null hypothesis $\left(H_{0}\right)$ should be accepted if $\mid$ Mann $-k \mid<z_{i-\infty / 2}$ at a 0.05 level of significance. $z_{i-\infty / 2}$, is the critical value of 
Mann-K from the standard normal table and for a 5\% significance level, the value of $z_{i-a / 2}$ is 1.96. In this study, significance levels of $p=0.05$ is applied.

\subsubsection{Detecting Farmers' Perception of Climate Change}

It has been noted that detecting perception of farmers on climate change is a difficult task in developing countries, especially in Africa. Farmers in the developed world have access to a wealth of climate and weather information and therefore they can easily learn about changes and variations in climate without having to sense them. However, the case is different in Africa where farmers use various traditional methods to forecast weather and climate. These farmers may detect long term climate fluctuations and changes only after they sense them, for which sensitivity matters individually (Abrha, 2015).

In this study therefore, following (Deressa et al., 2010); (Komba \& Muchapondwa, 2012); (Abrha, 2015) and (Mugagga, 2017), farmers were asked whether they noted changes in climate variables, mainly temperature and rainfall in the last ten years, as explained in Section 2.2. The data was entered into MS Excel and exported to STATA for basic descriptive analysis. Frequencies were the main statistical tool to describe the farmers' perception of changes in climatic trends. Simple correlations were then drawn of perception of the farmers and cross tabulated with their different socio-economic characteristics for instance age, gender, education levels, among others, to determine whether it varies among farmers of these different categories. Differences in the level of perception to climate change among farmers in different parts (station level and sub zonal level) of the study area were then descriptively assessed on the basis of these statistics to determine the spatial variation in perception of climate change. The perceptions of small holder farmers of climate change were then compared to the statistical trends obtained.

\subsubsection{Logistics Regression Analysis}

Farmers' perception of climate change is a precondition for effective adaptation. Evidence in Africa reveals that large numbers of agriculturalists already perceived hotter climate, less predictable rains with shorter duration and then started farm level responses. However, perceptions are context and location specific due to heterogeneity in factors that influence them such as culture, education, gender, age, resource endowments, agroecology, and institutional factors (Maddison, 2007); (Deressa et al., 2010); (Abrha, 2015).

The study therefore used the logistics regression model to analyse the determinants of farmers' perception of climate change following (Ndambiri, Ritho, \& Mbogoh, 2013) and (Abrha, 2015). This is because the dependent variable, farmers' perception of climate change, is dichotomous in nature, taking a value of 1 or 0. Although the Ordinary Least Squares (OLS) method may compute estimates for the binary choice models, certain assumptions of the classical regression model will be violated including non-normality of disturbances, heteroscedastic (different) variances of the disturbances and questionable value of $R^{2}$ as a measure of goodness of fit. For instance, given: 


$$
y_{i}=\beta_{0}+\beta_{i} \chi_{i}+\varepsilon_{i}
$$

where: $y_{1}=1$ if a farmer perceives climate change and $y_{1}=0$ if a farmer does not, $\beta_{0}$ is the parameter to be estimated, $X_{i}$ is the variable in question, $\varepsilon_{1}$ is disturbance term.

This model is a typical linear regression model but because the regression is binary, it is called a linear probability model (LPM). However, in a regression model, when the dependent variable is dichotomous in nature, taking the value 1 or 0 , use of linear probability models becomes a major challenge. This is because the predicted value can fall outside the relevant range of zero to one probability value. Thus, if linear probability models are used, the results may fail to meet statistical assumptions necessary to validate conclusions based on the hypothesis tested (Abrha, 2015). Logit and Probit Models are therefore recommended to overcome the challenges associated with LPM. These models use Maximum Likelihood Estimation (MLE) procedures and ensure that probabilities are bound between 0 and 1. Both Logit and Probit transformations estimate cumulative distribution, thereby eliminating the interval 0, 1 problem associated with LPM. The Logit cumulative function can be represented by:

$$
P_{i}=F\left(z_{i}\right)=\frac{1}{1+\mathrm{e}^{-z_{i}}}
$$

where $P_{i}$ is the probability that the $i^{\text {th }}$ person will be in I-first category, $Z_{i}=\beta_{0}+\beta_{i} x_{i}+\varepsilon_{i}$ where $\beta_{0}$ is intercept of the model; $\beta_{i}$ is model parameters to be estimated, $x_{i}$ are the independent variables and e represents base of natural $\operatorname{logarithms}$, which is approximately equal to 2.718 . In the equation above, $Z$ can range from positive infinity to negative infinity. The possibility of a farmer perceiving climate change lies between 0 and 1 . If we multiply both sides of the equation by $1+\mathrm{e}^{-z_{i}}$, we get:

$$
\left(1+\mathrm{e}^{-z_{i}}\right)=P_{1}=1
$$

Dividing by $P$ and then subtracting 1 lead to:

$$
\mathrm{e}^{-z_{1}}=\frac{1}{P_{i}}=\frac{1-P_{i}}{P_{i}}
$$

By definition; however, $\mathrm{e}^{-z_{i}}=\frac{1}{\mathrm{e}^{z_{i}}}$ so that the equation becomes:

$$
\mathrm{e}^{-z_{i}}=\frac{P_{1}}{1-P_{i}}
$$

By taking the natural logarithm of both sides of the equation, we get:

$$
Z_{i}=\log \left(\frac{P_{1}}{1-P_{i}}\right)
$$

In other words:

$$
\log \left(\frac{P_{1}}{1-P_{i}}\right)=z_{i}=\beta_{0}+\beta_{i} X_{i}
$$


This makes the logistic probability model. Therefore, it can be noted that the logistic model defined in Equation (2.12) is based on the logits of $Z$, which constitutes the stimulus index. Marginal effects can also be computed to show changes in probability when there is a unit change in independent variables. Marginal effects are computed as:

$$
\frac{\partial P_{k}}{\partial \chi_{k}}=\frac{\beta_{k} \mathrm{e}^{-z_{k}}}{\left(1+\mathrm{e}^{-z_{k}}\right)^{z}}
$$

Therefore, this logistic regression model was used to establish the determinants of perception to climate change. The dependent variable is farmers' perception of climate, a binary variable, indicating whether or not a farmer has perceived climate change. It was regressed on a set of explanatory variables (farmers' socioeconomic characteristics) namely, gender, age, farming experience, annual income level, group membership/social network, Farm equipment/technology, access to credit, access to extension services, educational level (Table 1).

\section{Results and Discussion}

\subsection{Climate Change Trends}

\subsubsection{Monthly Trends of Minimum Temperature, Maximum Temperature and Total Rainfall for the Kyoga Plains 1984-2014 \\ 1) At station Level}

Results of monthly trends of minimum temperature, maximum temperature and total rainfall at the station level reflect those at the individual meteorological stations within the agroecological area, that is, Tororo, Jinja (southern), Soroti and Lira (Northern).

Monthly minimum temperature trend for Tororo was positive during most of the months though not significant except for February when it was negative but not significant, Soroti registered a positive and significant trend throughout the year while lira had a positive and significant trend for most of the year except for the months of November when the trend was still positive though not significant. Its only Jinja that had a negative but non-significant trend for most of the months except March and April, implying a generally rising monthly trend in minimum temperature at the station level. This is more or less like the findings of (Limantol, Keith, Azabre, \& Lennartz, 2016) who found out a significant rise in minimum temperature in their study of farmers' perception and adaptation practice to climate variability and change in the Vea catchment of Ghana.

Monthly maximum temperature trends were equally positive though nonsignificant in most stations. Tororo for example had positive though non-significant trend for the months of January, February, April, June, and July while trends for the remaining months were negative but not significant. The trends for Jinja were positive though non-significant for most of the months except July when it was negative but non-significant. The trend for Soroti was positive though non-significant for the months of January, February, March, April, May, 
July and November. Its only September that had a significant negative trend while the remaining months equally registered negative but non-significant trends. In Lira on the other hand most of the months except March had negative trends with March being significantly negative. This implies a mixed trend in maximum temperature which is in contrast with the findings of (Nsubuga et al., 2011) who in a study of climatic trends at Namulonge, Uganda; 1947-2009, found an increasing trend in maximum temperature from January to December, with significant increases in the months of January, October and November.

Monthly total rainfall trends for Tororo were negative but not significant for the months of months of January, February, March, April, July and November while the trends for August, September, October and December were positive but not significant. The trends for Jinja were equally both positive and negative but not significant. The months of January, February, March, April, July and September, had negative trends while the rest had positive trends. In both Soroti and Lira, trends in total rainfall were negative though non-significant for most of the months except for July when a significant negative trend was registered in in Lira. This is tandem with (Djaman, Ndiaye, Koudahe, \& Bodian, 2018), who in a study in Madagascar, established that there were increasing trends in some months and non-significant trends in other months across the stations.

\section{2) At sub zonal Level}

Monthly minimum temperature, maximum temperature and total rainfall trends at the sub zonal level reflect those of the southern sub zone of the agroecological zone which combines results for the stations of Tororo and Jinja and the northern sub zone which combines results for the stations of Soroti and Lira as shown in Table 2.

Table 2. Monthly minimum temperature, maximum temperature and total rainfall trends at the sub zonal level for the Kyoga plains of Uganda 1984-2014.

\begin{tabular}{|c|c|c|c|c|c|c|c|c|c|c|c|c|}
\hline \multirow{3}{*}{ Month } & \multicolumn{6}{|c|}{ Southern sub zone } & \multicolumn{6}{|c|}{ Northern subzone } \\
\hline & \multicolumn{2}{|c|}{ min temp } & \multicolumn{2}{|c|}{$\max$ temp } & \multicolumn{2}{|c|}{ rain fall } & \multicolumn{2}{|c|}{$\min$ temp } & \multicolumn{2}{|c|}{$\max$ temp } & \multicolumn{2}{|c|}{ rain fall } \\
\hline & Kendal & $P$-value & Kendal & $P$ value & Kendal & $P$ value & Kendal & $P$ value & Kendal & $P$ value & Kendal & $P$ value \\
\hline Jan & 0.1142 & 0.1910 & 0.0978 & 0.2631 & -0.0180 & 0.8410 & 0.2332 & $0.0074^{* * *}$ & 0.0312 & 0.7243 & 0.0783 & 0.3714 \\
\hline $\mathrm{Feb}$ & 0.0693 & 0.4292 & 0.0529 & 0.5471 & -0.1348 & 0.1226 & 0.2628 & $0.0026^{* * *}$ & 0.0836 & 0.3398 & 0.0201 & 0.8220 \\
\hline Mar & 0.1015 & 0.2453 & 0.0825 & 0.3456 & -0.0122 & 0.8936 & 0.1544 & $0.0767^{*}$ & 0.0412 & 0.6397 & 0.0063 & 0.9467 \\
\hline Apr & 0.0402 & 0.6483 & 0.0999 & 0.2528 & -0.1793 & $0.0400^{* *}$ & 0.2173 & $0.0127^{\star *}$ & -0.0016 & 0.9903 & -0.1438 & $0.0995^{*}$ \\
\hline May & 0.0021 & 0.9854 & 0.0645 & 0.4615 & 0.0735 & 0.4016 & 0.2581 & $0.0030^{* * *}$ & 0.0360 & 0.6836 & -0.1512 & $0.0833^{*}$ \\
\hline June & 0.0122 & 0.8935 & 0.0994 & 0.2554 & 0.2126 & $0.0146^{* *}$ & 0.2507 & $0.0040^{* * *}$ & -0.0196 & 0.8267 & -0.550 & 0.5313 \\
\hline July & 0.0550 & 0.5310 & 0.0529 & 0.5471 & -0.0375 & 0.6705 & 0.2263 & $0.0094^{\star * *}$ & 0.0074 & 0.9370 & 0.0280 & 0.7520 \\
\hline Aug & -0.0079 & 0.9321 & -0.0227 & 0.7984 & 0.2195 & $0.0119^{* *}$ & 0.1809 & $0.0380^{* *}$ & -0.0402 & 0.6483 & 0.2242 & $0.0105^{* *}$ \\
\hline Sept & -0.0175 & 0.8457 & 0.0222 & 0.8030 & 0.0994 & 0.2557 & 0.2538 & $0.0036^{* * *}$ & -0.0724 & 0.4082 & 0.2041 & $0.0193^{* *}$ \\
\hline Oct & 0.0053 & 0.9563 & 0.0508 & 0.5633 & 0.1375 & 0.1155 & 0.1682 & $0.0537^{*}$ & -0.0317 & 0.7198 & 0.0857 & 0.3278 \\
\hline Nov & 0.0053 & 0.9563 & 0.0190 & 0.8314 & -0.0005 & 1.000 & 0.1740 & $0.0460^{* *}$ & -0.0074 & 0.9370 & 0.1386 & 0.1127 \\
\hline Dec & 0.0042 & 0.9660 & 0.0042 & 0.9660 & 0.0698 & 0.4961 & 0.2078 & $0.0171^{* *}$ & -0.0238 & 0.7890 & 0.0238 & 0.7891 \\
\hline
\end{tabular}

Kendal $=$ Mann-Kendal trend test, ${ }^{* *},{ }^{* *},{ }^{\star}$ Indicate significant trend at $1 \%, 5 \%$ and $10 \%$ level of significance respectively, calculated on the basis of the UNMA data series 1984-2014. 
Monthly minimum temperature trends for the southern sub zone were positive though not significant for the months of January, February, March, April, May, June, July, October, November and December while trends for the months of August and September were negative but not significant. There was a positive but non-significant trend in maximum temperature for all the months of the year except August, when the trend was negative but not significant.

The total rainfall trends in the southern sub zone were negative in January, February, March with April being significantly negative while the rest of the months were positive with June and July being significantly positive. Whereas these mixed trends in all the parameters are not significant in most of the cases, the fact that they are all positive especially in months like March, April and May which traditionally are known for being rainy, it is a significant indicator of changing climate.

The northern sub zone registered a positive and significant trend in minimum temperature for all the months of year, which is a clear sign of a general rise in minimum temperature. Maximum temperature trends were positive but non-significant in January, February, March, May and July while it was negative and non-significant during the remaining months.

Total rainfall trend on the other hand was positive and significant at the 0.05 level in August and September but it was negative though non-significant in April, May and June. Whereas this trend is non-significant, April and May are traditionally part of the long rainy season which starts in March and ends in June and so a negative trend here is an indicator of a changing climate.

Results of the Mann Kendall tests for monthly minimum temperature, maximum temperature and total rainfall in all the two sub zones show mixed trend which are in most cases not significant but significant in some cases and this is in line with (Gebre et al., 2013) who in a study in northern Ethiopia found out that both positive and negative trends, some significant and others non-significant in different subregions of northern Ethiopia.

\subsubsection{Seasonal Minimum Temperature, Maximum Temperature and Total Rainfall Trends for the Kyoga Plains 1984-2014 \\ 1) At the station level}

Results of seasonal trends of minimum temperature, maximum temperature and total rainfall at the station level reflect those at the individual meteorological stations within the agroecological area, that is, Tororo, Jinja, Soroti and Lira as shown in Table 3.

The seasonal minimum temperature trend is positive at most of the stations. In Tororo, the trend was positive for all the four seasons though it was only significant JJA season. The trend for Jinja was positive for the first two seasons, that is, DJF and MAM and negative but non-significant for JJA and SON. The trends in Soroti and Lira are positive and significant for all the seasons.

Seasonal maximum temperature trends for Tororo are positive and non-significant for the seasons of DJF and JJA while negative and non-significant 
Table 3. Seasonal minimum temperature, Maximum temperature and total rain fall trends at the station level for the Kyoga plains 1984-2014.

\begin{tabular}{|c|c|c|c|c|c|c|c|}
\hline \multirow{2}{*}{ Station } & \multirow{2}{*}{ season } & \multicolumn{2}{|c|}{ Min temperature } & \multicolumn{2}{|c|}{ Max Temperature } & \multicolumn{2}{|c|}{ Total rainfall } \\
\hline & & Kendall & $P$-value & Kendall & $\mathrm{P}$-value & Kendall & $P$-value \\
\hline \multirow{4}{*}{ TORORO } & DJF & 0.0713 & 0.3119 & 0.0428 & 0.5454 & -0.0687 & 0.3305 \\
\hline & MAM & 0.1410 & 0.0450 & -0.0201 & 0.7775 & 0.0157 & 0.8265 \\
\hline & JJA & 0.2101 & 0.0028 & 0.323 & 0.0602 & 0.1307 & $0.0639^{*}$ \\
\hline & SON & 0.1199 & 0.0883 & -0.0748 & 0.2883 & 0.1094 & 0.1209 \\
\hline \multirow{4}{*}{ JINJA } & DJF & 0.1508 & 0.0324 & 0.1760 & $0.0124^{* *}$ & 0.0112 & 0.8760 \\
\hline & MAM & 0.0075 & 0.9179 & 0.3216 & 0.0000 & -0.0278 & 0.6952 \\
\hline & JJA & -0.1377 & 0.0506 & 0.0358 & 0.6132 & 0.1276 & $0.0703^{*}$ \\
\hline & SON & -0.1286 & 0.0676 & 0.1947 & 0.0056 & 0.0486 & 0.4918 \\
\hline \multirow{4}{*}{ SOROTI } & DJF & 0.4308 & $0.0000^{* * *}$ & 0.1508 & 0.0323 & 0.0386 & 0.5857 \\
\hline & MAM & 0.3209 & $0.0000^{* * *}$ & 0.1765 & $0.0122^{* *}$ & -0.0863 & 0.2217 \\
\hline & JJA & 0.4755 & $0.0000^{* * *}$ & -0.0037 & 0.9602 & 0.0283 & 0.6903 \\
\hline & SON & 0.5320 & $0.0000^{* * *}$ & -0.1190 & 0.0911 & 0.0615 & 0.3843 \\
\hline \multirow{4}{*}{ LIRA } & DJF & 0.3177 & $0.0000^{* * *}$ & -0.0096 & 0.8942 & 0.0098 & 0.8917 \\
\hline & MAM & 0.3389 & $0.0000^{* * *}$ & -0.0806 & 0.2526 & -0.0535 & 0.4490 \\
\hline & JJA & 0.3621 & $0.0000^{* * *}$ & -0.0704 & 0.3182 & 0.0659 & 0.3507 \\
\hline & SON & 0.2543 & $0.0003^{* * *}$ & -0.0110 & 0.8783 & 0.1734 & $0.0139^{* *}$ \\
\hline
\end{tabular}

Kendal $=$ Mann-Kendal trend test; ${ }^{* * *},{ }^{* *},{ }^{*}$ Indicates significant trend at $1 \%, 5 \%$ and $10 \%$ level of significance respectively. Source: Calculated based on the UNMA data series 1984-2014.

for MAM and SON. The trends for Jinja are positive for all the seasons but significant for only MAM and SON. Maximum temperature trends for Soroti are positive but non-significant for DJF and MAM while negative non-significant for JJA and SON. Whereas there are some few negative trends here, the overall picture indicates an in increase in seasonal temperature which is tandem with (Djaman et al., 2018), who in a study in Madagascar, established that there were increasing trends in some seasons and non-significant trends in other seasons across the stations.

The seasonal trend of total rainfall for Tororo is negative for DJF and positive for the rest of the seasons but in all cases, the trend is not significant. In all the other stations, the trend of rainfall is negative for the MAM season and positive for the remaining seasons but not significant. Whereas this trend is not significant, it is critical because MAM is traditionally known as the long rainfall season in this area which supports the main agricultural production season and therefore any slight negative change affects the farmers very drastically, no wonder they were able to notice it in their perception. This is in contrast with (Nsubuga et al., 2014), who found that the MAM season which contributes a high percentage of the rainfall revealed mixed trends of decrease and increase that are not statistically significant. 


\section{2) At sub zonal levels}

Results of seasonal trends at the sub zonal level reflect those of the southern sub zone of the agroecological zone, combining results for the stations of Tororo and Jinja and the northern sub zone of the agroecological zone which combines results for the stations of Soroti and Lira as seen in Table 4.

The seasonal minimum temperature trend for the southern subzone is positive though non-significant for all the seasons. The seasonal minimum temperature trend in the northern subzone on the other hand is positive and significant in all the seasons. A positive trend in minimum temperature at both subzones with the trend in the northern subzone significantly positive during all the seasons is a clear indication of an increasing minimum temperature.

Maximum temperature trends for the southern subzone are positive though not significant in all the seasons. On the other hand, maximum temperature trends for the northern sub zone is positive though non-significant for the DJF and MAM seasons while negative and non-significant for JJA and SON. The results show an increase in both minimum and maximum temperatures in both the northern and southern sub zones which is a clear sign of an increasing temperature. This finding is consistent with that of (Nsubuga et al., 2011) who found an increasing trend in temperature in their study of climatic trends in Namulonge, Uganda.

The rainfall trend for the DJF and MAM seasons are negative and non-significant while positive and significant at the 0.05 level in JJA and positive but not significant in SON in the southern subzone. In the northern subzone, the rainfall trend is negative and non-significant for the MAM season while positive and significant for SON and positive but not significant DJF and JJA.

This is in line with (Nsubuga et al., 2014), who found mixed trends of decrease and increase in seasonal rainfall that is not statistically significant.

Table 4. Seasonal minimum temperature, Maximum temperature and total rain fall trends at the sub zonal level for the Kyoga plains 1984-2014.

\begin{tabular}{|c|c|c|c|c|c|c|c|}
\hline \multirow{2}{*}{ SUB ZONE } & \multirow{2}{*}{ SEASON } & \multicolumn{2}{|c|}{ MIN TEMPERATURE } & \multicolumn{2}{|c|}{ MAX TEMPERATURE } & \multicolumn{2}{|c|}{ TOTAL RAINFALL } \\
\hline & & Kendall & $P$ value & Kendall & $P$ value & Kendall & $P$ value \\
\hline \multirow{4}{*}{$\begin{array}{l}\text { SOUTHERN } \\
\text { SUB ZONE }\end{array}$} & DJF & 0.0552 & 0.2632 & 0.0544 & 0.2703 & -0.0281 & 0.5692 \\
\hline & MAM & 0.0369 & 0.4547 & 0.0750 & 0.1285 & -0.0102 & 0.8366 \\
\hline & JJA & 0.0180 & 0.7156 & 0.0418 & 0.3972 & 0.1228 & $0.0128^{* *}$ \\
\hline & SON & -0.0022 & 0.9661 & 0.0298 & 0.5460 & 0.0783 & 0.1126 \\
\hline \multirow{4}{*}{$\begin{array}{l}\text { NORTHERN } \\
\text { SUB ZONE }\end{array}$} & DJF & 0.1905 & $0.0001^{\star * *}$ & 0.3339 & 0.4919 & 0.0264 & 0.5933 \\
\hline & MAM & 0.1648 & $0.0008^{* * * *}$ & 0.1220 & 0.6567 & -0.0720 & 0.1448 \\
\hline & JJA & 0.2083 & $0.0000^{* * *}$ & -0.0184 & 0.7094 & 0.0454 & 0.3579 \\
\hline & SON & 0.1955 & $0.0001^{\star * *}$ & -0.0323 & 0.5128 & 0.1149 & $0.0199 * *$ \\
\hline
\end{tabular}

Kendal $=$ Mann-Kendal trend test; ${ }^{* *},{ }^{* *},{ }^{\star}$ Indicate significant trend at $1 \%, 5 \%$ and $10 \%$ level of significance respectively, calculated on the basis of the UNMA data series 1984-2014. 


\subsubsection{Annual Trends in Minimum Temperature, Maximum Temperature and Total Rainfall for the Kyoga Plains 1984-2014 \\ 1) At the station level}

There is a negative and significant trend in minimum temperature for the years, 1988 (0.009), 1991 (0.017), 1998 (0.012), 2002, 2006 (0.003), 2009 (0.010) and $2011(0.011)$ at Tororo. Soroti had a negative and significant minimum temperature trend in the years 1994, 1995, 1998, 2006, 2008 and 2014. Lira had a positive and significant minimum temperature trend for the years, 1984 (0.000), 1985 (0.000). It also had a significant negative minimum temperature trend in the years, $2006(0.011)$ and 2009 (0.19). Jinja had a significant positive trend for the years 1985, 1986, 1987 and 1988, (0.000) and a significant negative trend in 1990 (0.027), 2011 (0.013).

Tororo showed a significant negative trend in maximum temperature in the year 1997 (0.009), years were negative but not significant. Soroti had negative trend over the thirty years except for 1989, 1990, 1993 and 2005. However, in either cases, the trend is not significant. In the same way, Lira showed significant negative trends in maximum temperature in the years 1984 (0.000), 1985 (0.000), 1991 (0.028) 1992 (0.019), 1994 (0.005), 1995 (0.015), 2002 (0.013), 2005 (0.001), 2007 (0.013) and 2013 (0.004). The years 1987, 1988, 1989, 2008 and 2009 showed a positive but not significant trend. Jinja exhibited mainly negative trends in maximum temperature with significant trend in 1984, 1985, 1986, 1987, 1988 (0.000) and 2010 (0.006). The findings indicate a mix of trends in both maximum and minimum temperature which is in contrast with (Limantol et al., 2016) who found out an increasing temperature trend in their study of climate variability in the Vea catchment, Ghana.

Trends in total rainfall were equally mixed across the years in the different stations for instance in Tororo, there were increasing and decreasing non-significant trends in Soroti. In Lira, the trend was positive though non-significant for all the years except 1985 when it was negative but non-significant. Jinja on the other hand had significant positive trends at the 0.05 level of significance in 1992 and 2012 while the rest of the years had a mixed non-significant trend.

All the stations showed mixed, that is both positive (increasing) and negative (decreasing) mainly non-significant trends in all the climate parameters across the years. This is more or less in tandem with (Gebre et al., 2013) who in a study in northern Ethiopia established that in the last thirty years, rainfall had increased in some stations and decreased in others but with no statistical significance.

\section{2) At the sub zonal level}

Results of annual trends at the sub zonal level reflect those of the southern sub zone of the agroecological zone, combining results for the stations of Tororo and Jinja and the northern sub zone of the agroecological zone which combines results for the stations of Soroti and Lira.

The southern sub zone had mainly negative but non-significant trend in minimum temperature except for just eight out of the thirty years which had 
positive but non-significant trends. In the same way, the northern sub zone had only four out of the thirty years with a positive but non-significant minimum temperature trend while the remaining years had a negative though non-significant trend. This indicates that overall, there has not been much change in minimum temperature over the thirty years.

The southern sub zone had a generally negative but non-significant trend in annual maximum temperature for most of the years except two, 1993 and 2001, which had positive but equally non-significant trends. The northern sub zone on the other hand equally had a mainly negative but non-significant trend except for the year 1984 which had a significantly negative trend (0.0024). Only three years, 1988, 1989, and 1990 had positive but non-significant trend. This is in contrast with (Limantol et al., 2016) who in a study in the Vea catchment of Ghana, detected an increasing trend in temperature.

The total rainfall trend in the southern sub zone was mainly positive with the years 1992, 1997, 2000 and 2014 having significantly positive trends. However, there were equally negative trends in total rainfall with the year 1998 being negatively significant. The northern sub zone equally had mainly positive trends in annual total rainfall with the years 1993, 1997, 2002, 2009, 2011 and 2012 having significantly positive trends while a few years had negative but non-significant trends. The findings here show a largely positive trend in annual total rainfall which is more or less consistent with (Stampone et al., 2011) in their study of trends and variability in localized precipitation around Kabale, Uganda.

\subsubsection{Decadal Trends of Minimum Temperature, Maximum Temperature and Total Rainfall for the Kyoga Plains 1984-2014 \\ 1) At the station level}

Decadal minimum temperature, maximum temperature and total rainfall trends at station level are shown in Table 5 and from the table, minimum temperature for Tororo are positive and significant for the 2004-2014 decade while trends in the other decades were equally positive though non-significant, Soroti had a negative but non-significant trend for the 1984-1993 decade while the other decades were positive with the 2004-2014 decade being significantly positive at the 0.05 level of significance. Lira had a negative but non-significant trend during the 2004-2014 decade while the other decades were positive with the 1984-1993 decade being significantly positive at the 0.01 level of significance. Jinja had a negative trend during the 2004-2014 decade while the other decades were positive with 1984-1993 decade being significantly positive at the 0.05 level of significance. All the stations registered mixed trends in minimum but there is an indication of general rise in minimum temperature.

Tororo had a negative but non-significant trend in maximum temperature during the 2004-2014 decade while the other decades registered a positive though non-significant trend. A significant negative trend in maximum temperature occurred in Lira during the 1984-1993 decade. The other stations across 
Table 5. Decadal minimum temperature, maximum temperature and total rainfall trends at station level for the Kyoga plains of Uganda, 1984-2014.

\begin{tabular}{|c|c|c|c|c|c|c|c|c|c|c|c|c|}
\hline \multirow{2}{*}{$\begin{array}{l}\text { Climatic } \\
\text { Elements }\end{array}$} & \multicolumn{3}{|c|}{ TORORO } & \multicolumn{3}{|c|}{ SOROTI } & \multicolumn{3}{|c|}{ LIRA } & \multicolumn{3}{|c|}{ JINJA } \\
\hline & 1984-1993 & $1994-2003$ & 2004-2014 & 1984-1993 & $1994-2003$ & 2004-2014 & 1984-1993 & 1994-2003 & 2004-2014 & 1984-1993 & $1994-2003$ & 2004-2014 \\
\hline $\begin{array}{c}\text { Monthly } \\
\text { minimum } \\
\text { temperature } \\
\text { (Kendal) }\end{array}$ & 0.0952 & 0.0542 & 0.1147 & -0.0202 & 0.1303 & 0.0161 & 0.3368 & 0.0109 & -0.0330 & 0.0905 & 0.1277 & -0.0413 \\
\hline p-values & 0.1210 & 0.3780 & $0.0500^{* *}$ & 0.7431 & $0.0337^{\star *}$ & 0.7845 & $0.0000^{* * *}$ & 0.8605 & 0.5744 & 0.1412 & $0.0376^{* *}$ & 0.4813 \\
\hline $\begin{array}{c}\text { Monthly } \\
\text { maximum } \\
\text { temperature } \\
\text { (Kendal) }\end{array}$ & 0.0650 & 0.0490 & -0.0544 & 0.1371 & 0.0380 & -0.0851 & -0.3076 & -0.0328 & 0.0131 & -0.0658 & -0.0188 & -0.0407 \\
\hline p-values & 0.2907 & 0.4257 & 0.3536 & 0.0256 & 0.5378 & 0.1462 & $0.0000^{* * *}$ & 0.5947 & 0.8246 & 0.2846 & 0.7612 & 0.4873 \\
\hline $\begin{array}{l}\text { Monthly } \\
\text { total rainfall } \\
\text { (Kendal) }\end{array}$ & -0.0466 & -0.0256 & -0.0127 & 0.0246 & 0.0014 & 0.0318 & 0.0178 & -0.0140 & 0.0505 & -0.0095 & -0.0104 & 0.0178 \\
\hline p-values & 0.4489 & 0.6781 & 0.8295 & 0.6898 & 0.9836 & 0.5882 & 0.7738 & 0.8214 & 0.3889 & 0.8785 & 0.8678 & 0.7624 \\
\hline
\end{tabular}

Kendal $=$ Mann-Kendal trend test; ${ }^{* * *},{ }^{* *}$ Indicate significant at $1 \%$ and $5 \%$ level of significance respectively, calculated on the basis of the UNMA data series 1984-2014

the decades registered a mixture of positive and negative non-significant trends. These findings indicate a mixed trend in both minimum and maximum temperature in the different stations. This is in tandem with (Jury \& Funk, 2013) who found out a significant positive trend in temperature in his study on climate trends in southern Africa.

The total rainfall trend for Tororo is negative throughout the decades while the trend for Soroti is positive all through. The trend for Lira was negative and significant for the 1984-1993 decade and positive but not significant for the other two decades. Jinja on the other hand had a positive trend for the 2004-2014 decade and negative but not significant trend for the other decades. The results of decadal rainfall show a mixed trend which is in line with (Jury \& Funk, 2013) who found a mixed trend in rain in his study on climate trends in southern Africa.

\section{2) At the sub zonal level}

Results of the sub zonal level reflect those of the southern sub zone of the agroecological zone which combines results for the stations of Tororo and Jinja and the northern sub zone of the agroecological zone which combines results for the stations of Soroti and Lira as shown in Table 6.

Minimum temperature trend for the southern subzone was positive though non-significant throughout the decades while for the northern subzone sub zone mostly positive and equally non-significant except for the 2004-2014 decade, which had a negative but equally non-significant trend.

Maximum temperature trend was positive but not significant in the southern sub zone during the 2004-2014 decade while the remaining decades had negative 
Table 6. Decadal minimum temperature, maximum temperature and total rainfall trends at sub zonal level for the Kyoga plains of Uganda, 1984-2014.

\begin{tabular}{cccccccc}
\hline \multirow{2}{*}{ SUB ZONE } & \multirow{2}{*}{ DECADE } & \multicolumn{3}{c}{ MIN TEMPERATURE MAX TEMPERATURE } & \multicolumn{2}{c}{ TOTAL RAINFALL } \\
\cline { 3 - 8 } & & Kendal & P-value & Kendal & p-value & Kendal & P-value \\
\hline \multirow{2}{*}{ SOUTHERN } & $1984-1993$ & 0.0462 & $\mathbf{0 . 2 8 3 9}$ & -0.0002 & $\mathbf{0 9 9 6 8}$ & -0.0002 & $\mathbf{0 . 9 9 6 8}$ \\
& $1994-2003$ & 0.0453 & $\mathbf{0 . 2 9 3 8}$ & 0.0075 & $\mathbf{0 . 8 6 1 9}$ & 0.0075 & $\mathbf{0 . 8 6 1 9}$ \\
& $2004-2014$ & 0.0183 & $\mathbf{0 . 6 5 6 9}$ & -0.0237 & $\mathbf{0 . 5 6 5 1}$ & -0.0237 & $\mathbf{0 . 5 6 5 1}$ \\
& $1984-1993$ & 0.0792 & $\mathbf{0 . 0 6 5 5}$ & -0.0532 & $\mathbf{0 . 2 1 7 1}$ & -0.0532 & $\mathbf{0 . 2 1 7 1}$ \\
NORTHERN & $1994-2003$ & 0.0351 & $\mathbf{0 . 4 1 5 3}$ & 0.0013 & $\mathbf{0 . 9 7 6 8}$ & 0.0013 & $\mathbf{0 . 9 7 6 8}$ \\
& $2004-2014$ & -0.0042 & $\mathbf{0 . 9 1 9 1}$ & -0.0179 & $\mathbf{0 . 6 6 3 0}$ & -0.0179 & $\mathbf{0 . 6 6 3 0}$ \\
\hline
\end{tabular}

Kendal $=$ Mann-Kendal trend test, ${ }^{* * *},{ }^{* *},{ }^{*}$ indicate significant trend at $1 \%, 5 \%$ and $10 \%$ level of significance respectively, calculated on the basis of the UNMA data series 1984-2014.

but not significant trends. The northern sub zone equally had a positive but not significant trend during the 1984-1993 decade while the remaining decades had a negative but not significant trend. This trend though non-significant is an indicator of a general rise in temperature in the entire agroecological zone which is almost in line with those of IPCC 2001a, (Metz, Davidson, Swart, \& Pan, 2001) to the effect that there is a general rise in temperature across the decades and 1990 was found to be the warmest decade.

The total rainfall trend was positive but not significant in both subzones during the 1994-2003 decade while the other decades had negative but non-significant trend. This result indicates a general decline in rainfall just as was the case in (Gebre et al., 2013).

\subsection{Perception of Farmers on Climate Change Trends}

To investigate perception of farmers on climate change, the farmers were asked to state what they had observed regarding long-term changes in the climate variables, temperature and rainfall and specify what they had observed: increase, decrease, no change or fluctuation in seasonal precipitation.

Generally, an average of $67 \%$ and $56.8 \%$ of respondents observed the trend of declining rainfall and increasing temperature. Chi-square test results

$X^{2}(1, N=384)=135.76, p<0.01$ for rainfall and $X^{2}(1, N=384)=109.57, p<0.01$ for temperature show that perceptions of farmers significantly vary by sub zone of the agroecological zone. Whereas $56.3 \%$ of respondents from the southern sub zone of the agroecological area perceived a decline in rainfall, $42.7 \%$ of respondents from the northern sub zone realized that rainfall was decreasing and whereas 40.6 of the respondents from the northern sub zone realized that temperature was increasing, $52.1 \%$ of the respondents in the southern sub zone realized that temperature was increasing. Variations in rainfall characteristics between the two sub zones of the agroecological area and the spatio-temporal variations in climate related events, such as localized droughts, negative anomalies and rainfall irregularities, may have in- 
fluenced farmers to vary senses to climate trends. This finding is more or less like that of (Mugagga, 2017) who in a study of perceptions and response actions of smallholder coffee farmers to climate variability in montane ecosystems in eastern Uganda found out that over $68 \%$ of the smallholder coffee farmers perceived winds and droughts as having significantly increased, while $56 \%$ and over $84 \%$ perceived temperature and rainfall to have moderately increased in the last couple of years.

Furthermore, farmers were asked to specify what type of change they observed for rainfall and temperature in the last ten years. There was some variation in perception both in rainfall and temperature. Out of all the respondents, only $11 \%$ and $29 \%$ in the northern sub zone saw temperature as constant and fluctuating respectively while $8.3 \%$ and $18.8 \%$ of the respondents in the southern sub zone saw temperature as constant and fluctuating, respectively. In the same vain, only $16.7 \%$ and $12.5 \%$ of the respondents from the northern sub zone, perceived rainfall to be constant and fluctuating while $8.3 \%$ and $18.8 \%$ of the respondents from the southern sub zone perceived rainfall to have been constant and fluctuating respectively. The variation in perception of both temperature and rainfall was significant at the sub zonal level, $\chi^{2}(1, N=384)=109.6, p<0.001$.

On the other hand, about $28.1 \%$ of farmers from the northern sub zone and $20.8 \%$ from the southern sub zone presumed an increasing trend in rainfall, with a significant variation across study area.

Knowing whether farmers' perceptions on climate change are consistent with reality (statistical findings) is an important step in adaptation practices. Perception should be consistent with realities in order to have effective adaptation practices. When farmers' perceptions are different from reality, their decisions to respond to climate change at the right time and space would deviate, becoming risky for farmers (Abrha, 2015).

The Mann-Kendall trend results for the overall agroecological zone show a decrease in monthly rainfall and an increasing monthly temperature in the three decades (1984-2014) across all scales. Therefore, perceptions of farmers on seasonal rainfall for the three decades can be considered nearly consistent with Mann Kendall analysis results. This is in tandem with (Abrha, 2015), (Selase, Xinhai, \& Worlanyo, 2017), (Mubangizi et al., 2017) and (Mubiru, 2018).

Discussions with farmers revealed that they evaluate rainfall and temperature in view of whether it has affected their production at a particular time. Changes in quantity of rain, the timing of onset, cessation dates, and frequency and duration of dry spells might cause serious effects in farmers' production and livelihoods. In view of this, rainfall and temperature in the study area was erratic and unreliable, resulting in crop reduction and failure. This is in tandem with (Faostat, 2009), (Abrha, 2015), (Mubiru, 2018).

On the association between farmer socioeconomic characteristics and perception, cross tabulation with chi square test was carried out. To this end, at the agroecological (zonal) level, about $64 \%$ of the farmers who perceived climate 
change were found in the category of those who belonged to social groups and $80.7 \%$ of them had at least primary education. The variations in perception between those who belonged to social groups and who did not, was significant at $X^{2}(N=118)=5.35, p<0.05$. This is in direct contrast with the findings of (Selase et al., 2017) who found a significant negative relationship between belonging to a group and perception of climate change.

At the sub zonal level, in both the northern and southern sub zones, the association between perception and farmer socioeconomic characteristics did not show any significance. This implies that there is no significant spatial variation in the socioeconomic determinants of the perception of climate change among the farmers across the agroecological zone.

\subsection{Determinants of Perception on Climate Change}

Farmers should be able to perceive changes in the climate if they are to respond to it effectively through adaptation practices. It is through adaptation that they can minimize adverse effects of climate change in their agricultural production in particular and livelihoods in general. However, ability of farmers to perceive climate change is affected by various socioeconomic and institutional factors (Abrha, 2015). Table 7 presents the logistics regression coefficient together with marginal effects after the dependent variable (perception) was regressed on a set of explanatory variables (farmers' socioeconomic characteristics) that were discussed in section 2.3.3.

At the sub zonal level, in the southern sub zone, access to extension workers had a negative and significant (at 0.05 level) relationship with perception of climate change, implying that the farmers who had no access to extension workers were able to perceive climate change. This is contrary to the findings of (Uddin, Bokelmann, \& Dunn, 2017), who note that extension workers offer training on environmental and farm management issues hence are able to improve the farmers knowledge and skills.

In the northern sub zone on the other hand, farming experience had a positive and significant (at 0.05 level) relationship with perception of climate change. This implies that farmers who had a longer experience in farming were able to perceive climate change more than their counterparts with less experience. This is in line with the finding that experience gives them the ability to develop knowledge and skill that helps them to sense risks better (Maddison, 2007).

Furthermore, in the northern sub zone, belonging to a group had a positive and significant (at 0.05 level) relationship with perception of climate change. This implies that farmers who belonged to a group were able to perceive climate change more than those that did not belong to any group. This is in line with the findings of (Maddison, 2007); (Abrha, 2015); (Uddin et al., 2017).

At the zonal level, farming experience had a negative and significant (at 0.05 level) relationship with perception of climate, implying that farmers who have been in the trade for a longer time are more able to perceive climate change than 
Table 7. Binomial logistic regression model on the determinants of small holder farmers' perception of climate change (Base outcome was NO).

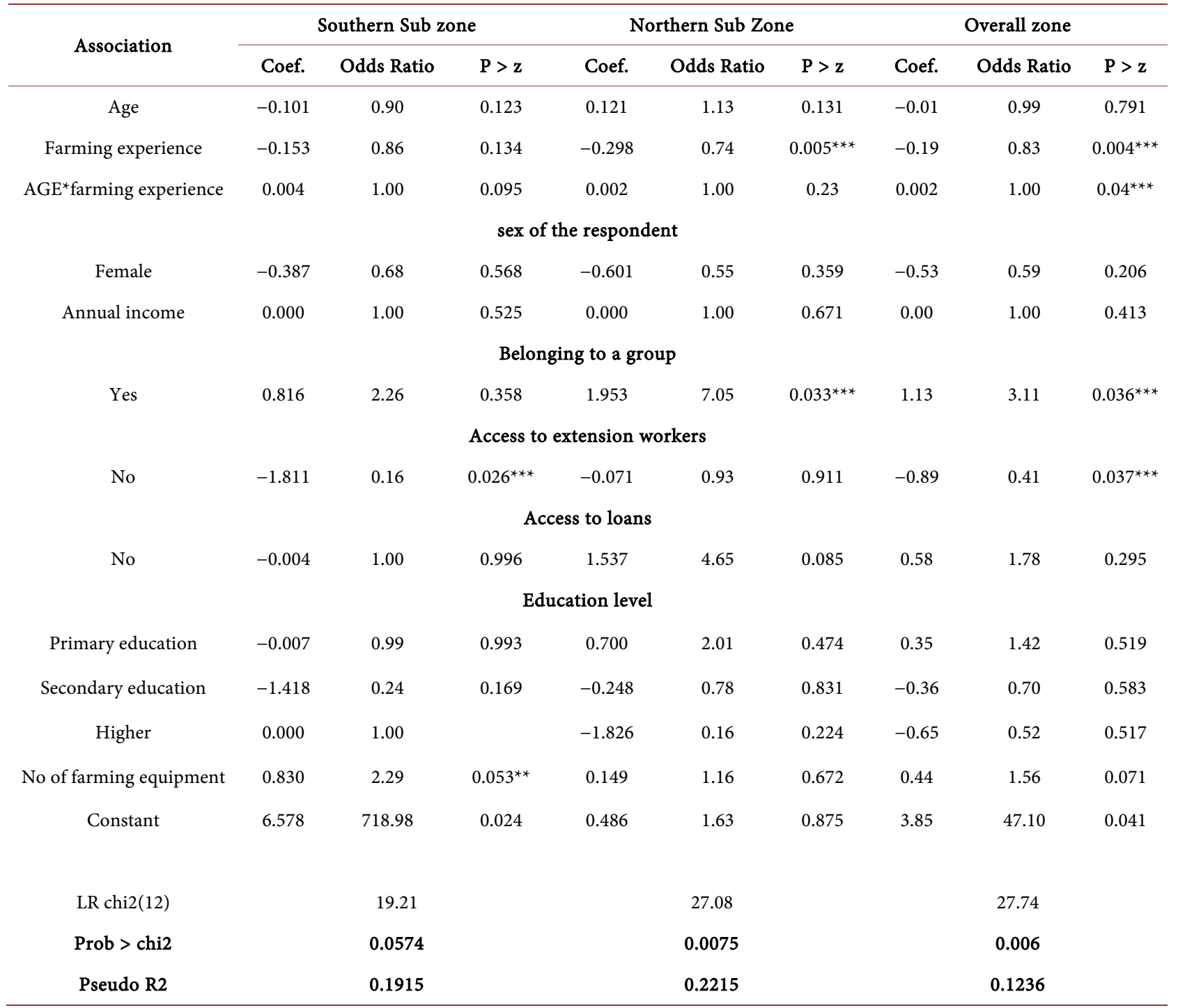

Source: Data from field survey 2017/18.

those that have been it for a shorter time. This is contrary the findings of (Uddin et al., 2017; Abrha, 2015).

In addition, at the zonal level, access to extension workers had a negative and significant (at the 0.05 level) relation with perception of climate change. Farmers who had no access to extension workers were able to perceive climate change despite lack of access to training on environmental and farm management issues that are usually given by extension workers. This is contrary to the findings of (Uddin et al., 2017).

Belonging to a group had a positive and significant (at the 0.05) relationship with perception of climate change. Group membership enables farmers to interact widely with each other and in the process learn from one another and therefore help them acquire knowledge and skills including that of climate 
change. This however contradicts the findings of (Selase et al., 2017) who found a negative relationship between belonging to a group and climate change perception.

Given the collinearity of age and farming experience in regard to their effect on farmers' perception of climate change, the two variables were combined after the initial analysis to test their joint impact on farmers' perception and the result showed a positive and significant (at 0.05) relation with perception of climate change. This is in line with (Deressa, Hassan, \& Ringler, 2011) who observed that farming experience can be derived from the age of the farmer.

\section{Conclusions and Policy Recommendations}

Mann-Kendall trend analysis results for monthly, seasonal, annual and decadal at station, sub zonal, and zonal level have shown significant insights about how regional climate is changing in the Kyoga plains. On the whole there is a rise in both minimum and maximum temperature but this was found to be statistically non-significant at the 0.05 level of significance at most of the stations studied. There was a decline in the total rainfall at all levels, that is, monthly, seasonal, annual and decadal though the trend was equally statistically non-significant at the 0.05 level of significance. This agrees with the perception of the local farmers at the overall agroecological (zonal) level where about $67 \%$ of respondents perceived a trend in declining rainfall and $56.8 \%$, increasing temperature in their localities.

However, there was a significant spatial variation in the perception of climate change trends among respondents in the different sub zones of the agroecological area with $56.3 \%$ of the farmers in the southern sub zone realizing that rainfall was declining and $52.1 \%$ realized that temperature was increasing and $42 \%$ in the northern sub zone realizing that rainfall was increasing while $40.6 \%$ realized that temperature was increasing.

Perception of farmers was influenced by various factors. Overall at the zonal (agroecological) level, belonging to a group or social network had a significant positive effect on farmers' perceptions of climate change. Access to extension workers and farming experience showed significant negative effects on perception to climate change.

There was also a spatial variation in the factors that influence farmers perception on climate change. In the southern sub zone, the number of farming equipment showed a positive and significant effect on perception (at 0.09 confidence level) while access to extension workers showed a significant negative effect on perception (at 0.05 confidence level). In the northern sub zone, belonging to a group or social network had a significant positive effect on perception of climate change while farming experience showed a significant negative effect on perception.

Subsequently, the factors that were found to affect farmers' perception of climate change, that is, age, belonging to a group, farming experience and access to extension workers are related to institutional and infrastructural developments. 
Therefore, a lot has to be done in awareness creation work on climate change at the local level particularly with experienced farmers who may not be open to new innovations and technologies perhaps due to the feeling that they know it all, given their long experience.

There is also need to evaluate the effectiveness of the extension workers since it would be a priori that their presence would make the farmers have good knowledge and skills of farm management and the environment that would enhance their perception of climate change and the capacity to develop adaptation strategies. There is need to improve their numerical strength, level of skills and work facilities for better performance so to be able to enhance farmers' ability to perceive climate change and in so doing, develop better adaptation mechanisms.

Besides, given that there is a significant spatial variation in the factors that influence perception of climate change, that is, in the different sub zones of the agroecological area, there is need to design location specific intervention measures to be taken in each of the sub zones other than the uniform measures for the entire zone or region, which is common in literature. Accordingly, substantial work related to local knowledge of rainfall, temperature and drought variations, environmental conservation work, among others, are suggested in order to combat the effect of this threatening trend of climate change and improve livelihoods of the people in the study area.

\section{Acknowledgements}

The authors are grateful to Swedish International Development Agency (Sida) and Makerere University under Sida Grant Contribution No: 5180060 for funding PhD studies for the first author.

We also appreciate Gulu University, the employing University of the first author for granting him study leave during his $\mathrm{PhD}$ studies at Department of Geography, Geo informatics and Climatic Sciences, School of Forestry Environmental and Geographical Sciences, College of Agricultural Sciences, Makerere University, Uganda.

\section{Conflicts of Interest}

The authors declare no conflicts of interest regarding the publication of this paper.

\section{References}

Abraha, M. G. (2015). Climate Change and Farmers Adaptation Practices in Ethiopia: A Study in Southern Tigray Region.

Abrha, M. G. (2015). Local Climate Trends and Farmers' Perceptions in Southern Tigray, Northern Ethiopia. International Journal of Environment and Sustainability, 4, 262-277. https://doi.org/10.24102/ijes.v4i3.563

Authority NEM (2006). State of the Environment Report for Uganda. Kampala: NEMA.

Bernstein, L., Bosch, P., Canziani, O., Chen, Z., Christ, R., \& Riahi, K. (2008). IPCC, 2007: Climate Change 2007: Synthesis Report: IPCC. 
Bhuyan, M. D. I., Islam, M. M., \& Bhuiyan, M. E. K. (2018). A Trend Analysis of Temperature and Rainfall to Predict Climate Change for Northwestern Region of Bangladesh. American Journal of Climate Change, 7, 115.

https://doi.org/10.4236/ajcc.2018.72009

Blackwell, M., \& Glynn, A. (2017). How to Make Causal Inferences with Time-Series Cross-Sectional Data under Selection on Observables. Technical Report Working Paper. https://doi.org/10.2139/ssrn.3176910

Bomuhangi, A., Nabanoga, G., Namaalwa, J. J., Jacobson, M. G., \& Abwoli, B. (2016). Local Communities' Perceptions of Climate Variability in the Mt. Elgon Region, Eastern Uganda. Cogent Environmental Science, 2, Article ID: 1168276.

https://doi.org/10.1080/23311843.2016.1168276

Chombo, O., Lwasa, S., \& Makooma, T. M. (2018). Spatial Differentiation of Small Holder Farmers' Vulnerability to Climate Change in the Kyoga Plains of Uganda. American Journal of Climate Change, 7, 624. https://doi.org/10.4236/ajcc.2018.74039

Deressa, T. T., Hassan, R. M., \& Ringler, C. (2011). Perception of and Adaptation to Climate Change by Farmers in the Nile Basin of Ethiopia. The Journal of Agricultural Science, 149, 23-31. https://doi.org/10.1017/S0021859610000687

Deressa, T. T., Ringler, C., \& Hassan, R. M. (2010). Factors Affecting the Choices of Coping Strategies for Climate Extremes. The Case of Farmers in the Nile Basin of Ethiopia IFPRI Discussion Paper 1032.

Djaman, K., Koudahe, K., \& Ganyo, K. K. (2017). Trend Analysis in Annual and Monthly Pan Evaporation and Pan Coefficient in the Context of Climate Change in Togo. Journal of Geoscience and Environment Protection, 5, 41.

https://doi.org/10.4236/gep.2017.512003

Djaman, K., Ndiaye, P., Koudahe, K., \& Bodian, A. (2018). Spatial and Temporal Trend in Monthly and Annual Reference Evapotranspiration in Madagascar for the 1980-2010. International Journal of Hydromechatronics, 2, 110-120.

https://doi.org/10.15406/ijh.2018.02.00058

Egeru, A., Osaliya, R., MacOpiyo, L., Mburu, J., Wasonga, O., Barasa, B., Majaliwa Mwanjalolo, G.-J. et al. (2014). Assessing the Spatio-Temporal Climate Variability in Semi-Arid Karamoja Sub-Region in North-Eastern Uganda. International Journal of Environmental Studies, 71, 490-509. https://doi.org/10.1080/00207233.2014.919729

Eike, L., Roeland, K., Swen, B., Sang, J., \& Musau, J. (2014). Climate Change Impacts on Ecosystems of Mt. Elgon. Adapt EA Project Technical Report, World Agroforestry Centre/CIFOR/Rockefeller Foundation.

Elbehri, A., Genest, A., \& Burfisher, M. E. (2011). Global Action on Climate Change in Agriculture: Linkages to Food Security, Markets and Trade Policies in Developing Countries. Trade and Markets Division, Food and Agriculture Organization of the United Nations.

Epule, T. E., Ford, J. D., Lwasa, S., \& Lepage, L. (2017). Vulnerability of Maize Yields to Droughts in Uganda. Water, 9, 181. https://doi.org/10.3390/w9030181

Faostat, F. (2009). Statistical Databases. Food and Agriculture Organization of the United Nations.

Foster, A. D., \& Rosenzweig, M. R. (2004). Agricultural Productivity Growth, Rural Economic Diversity, and Economic Reforms: India, 1970-2000. Economic Development and Cultural Change, 52, 509-542. https://doi.org/10.1086/420968

Gebre, H., Kindie, T., Girma, M., \& Belay, K. (2013). Trend and Variability of Rainfall in Tigray, Northern Ethiopia: Analysis of Meteorological Data and Farmers' Perception. Academia Journal of Agricultural Research, 1, 088-100. 
Jury, M. R., \& Funk, C. (2013). Climatic Trends over Ethiopia: Regional Signals and Drivers. International Journal of Climatology, 33, 1924-1935.

https://doi.org/10.1002/joc.3560

Kizza, M., Rodhe, A., Xu, C.-Y., Ntale, H. K., \& Halldin, S. (2009). Temporal Rainfall Variability in the Lake Victoria Basin in East Africa during the Twentieth Century. Theoretical and Applied Climatology, 98, 119-135.

https://doi.org/10.1007/s00704-008-0093-6

Komba, C., \& Muchapondwa, E. (2012). Adaptation to Climate Change by Smallholder Farmers in Tanzania. Economic Research Southern Africa (ERSA) Working Paper 299.

Limantol, A. M., Keith, B. E., Azabre, B. A., \& Lennartz, B. (2016). Farmers' Perception and Adaptation Practice to Climate Variability and Change: A Case Study of the Vea Catchment in Ghana. SpringerPlus, 5, 830. https://doi.org/10.1186/s40064-016-2433-9

Lwasa, S., Mugagga, F., Wahab, B., Simon, D., Connors, J., \& Griffith, C. (2014). Urban and Peri-Urban Agriculture and Forestry: Transcending Poverty Alleviation to Climate Change Mitigation and Adaptation. Urban Climate, 7, 92-106.

https://doi.org/10.1016/j.uclim.2013.10.007

Maddison, D. (2007). The Perception of and Adaptation to Climate Change in Africa. Washington DC: The World Bank. https://doi.org/10.1596/1813-9450-4308

McSweeney, C., New, M., Lizcano, G., \& Lu, X. (2010). The UNDP Climate Change Country Profiles: Improving the Accessibility of Observed and Projected Climate Information for Studies of Climate Change in Developing Countries. Bulletin of the American Meteorological Society, 91, 157-166. https://doi.org/10.1175/2009BAMS2826.1

Metz, B., Davidson, O., Swart, R., \& Pan, J. (2001). Climate Change 2001: Mitigation: Contribution of Working Group III to the Third Assessment Report of the Intergovernmental Panel on Climate Change (Vol. 3). Cambridge: Cambridge University Press.

Ministry of Water and Environment U. (2002). Initial National Communication of Uganda to the Conference of the Parties to the United Nations Framework Convention on Climate Change. Paper Presented at the Conference of Parties to the UNFCCC. http://unfccc.int/resource/docs/natc/uganc1.pdf

Mubangizi, N., Kyazze, F., \& Mukwaya, P. (2017). Smallholder Farmers' Perception and Adaptation to Rainfall Variability in Mt. Elgon Region, Eastern Uganda. International Journal of Agricultural Extension, 5, 103-117.

Mubiru, D. (2018). Sustainable Intensification of Maize-Legume Cropping Systems for Food Security in Eastern and Southern Africa.

Mugagga, F. (2017). Perceptions and Response Actions of Smallholder Coffee Farmers to Climate Variability in Montane Ecosystems. Environment and Ecology Research, 5, 357-366. https://doi.org/10.13189/eer.2017.050505

Ndambiri, H. K., Ritho, C. N., \& Mbogoh, S. G. (2013). An Evaluation of Farmers' Perceptions of and Adaptation to the Effects of Climate Change in Kenya. International Journal of Food and Agricultural Economics, 1, 75.

Nsubuga, F. W., Botai, O., Olwoch, J. M., Rautenbach, C. D., Bevis, Y., \& Adetunji, A. O. (2014). The Nature of Rainfall in the Main Drainage Sub-Basins of Uganda. Hydrological Sciences Journal, 59, 278-299. https://doi.org/10.1080/02626667.2013.804188

Nsubuga, F., Olwoch, J. M., \& de W Rautenbach, C. (2011). Climatic Trends at Namulonge in Uganda: 1947-2009. Journal of Geography and Geology, 3, 119.

https://doi.org/10.5539/jgg.v3n1p119 
Okonya, J. S., Syndikus, K., \& Kroschel, J. (2013). Farmers' Perception of and Coping Strategies to Climate Change: Evidence from Six Agro-Ecological Zones of Uganda. Journal of Agricultural Science, 5, 252. https://doi.org/10.5539/jas.v5n8p252

Önöz, B., \& Bayazit, M. (2012). Block Bootstrap for Mann-Kendall Trend Test of Serially Dependent Data. Hydrological Processes, 26, 3552-3560. https://doi.org/10.1002/hyp.8438

Patiño, L., \& Gauthier, D. A. (2009). Integrating Local Perspectives into Climate Change Decision Making in Rural Areas of the Canadian Prairies. International Journal of Climate Change Strategies and Management, 1, 179-196.

https://doi.org/10.1108/17568690910955630

Rosenzweig, C., \& Tubiello, F. N. (2007). Adaptation and Mitigation Strategies in Agriculture: An Analysis of Potential Synergies. Mitigation and Adaptation Strategies for Global Change, 12, 855-873. https://doi.org/10.1007/s11027-007-9103-8

Selase, A., Xinhai, L., \& Worlanyo, A. (2017). Climate Variability: Cocoa Farmers Perception and Coping Strategies, Suaman District of Ghana as the Focal Point. Environment Pollution and Climate Change, 1, 4. https://doi.org/10.4172/2573-458X.1000141

Stampone, M. D., Hartter, J. N., Chapman, C. A., \& Ryan, S. J. (2011). Trends and Variability in Localized Precipitation around Kibale National Park, Uganda, Africa. Research Journal of Environmental and Earth Sciences, 3, 14-23.

Stocker, T., Qin, D., Plattner, G., Tignor, M., Allen, S., Boschung, J., Midgley, P. et al. (2013). IPCC, 2013: Climate Change 2013: The Physical Science Basis. Contribution of Working Group I to the Fifth Assessment Report of the Intergovernmental Panel on Climate Change (1535 p.). Cambridge and New York: Cambridge Univ. Press.

Tabari, H., \& Talaee, P. H. (2011). Recent Trends of Mean Maximum and Minimum Air Temperatures in the Western Half of Iran. Meteorology and Atmospheric Physics, 111, 121-131. https://doi.org/10.1007/s00703-011-0125-0

Turyahabwe, N., Tumusiime, D. M., Kakuru, W., \& Barasa, B. (2013). Wetland Use/Cover Changes and Local Perceptions in Uganda. Sustainable Agriculture Research, 2, 95. https://doi.org/10.5539/sar.v2n4p95

Uddin, M. N., Bokelmann, W., \& Dunn, E. S. (2017). Determinants of Farmers' Perception of Climate Change: A Case Study from the Coastal Region of Bangladesh. American Journal of Climate Change, 6, 151. https://doi.org/10.4236/ajcc.2017.61009

Wortmann, C. S., \& Eledu, C. S. (1999). Uganda's Agroecological Zones: A Guide for Planners and Policy Marker.

Yue, S., \& Hashino, M. (2003). Long Term Trends of Annual and Monthly Precipitation in Japan. Journal of the American Water Resources Association, 39, 587-596. https://doi.org/10.1111/j.1752-1688.2003.tb03677.x

Yue, S., \& Wang, C. (2004). The Mann-Kendall Test Modified by Effective Sample Size to Detect Trend in Serially Correlated Hydrological Series. Water Resources Management, 18, 201-218. https://doi.org/10.1023/B:WARM.0000043140.61082.60 